\title{
Domestic Violence against Women in Turkey, What Did Women Say?
}

\author{
Gulten Kaptan*, Ayse Yalili, Nilgun Vardarli and Çiğdem \\ Fulya Dönmez \\ Istanbul Arel University, School of Health Sciences, Department of \\ Nursing, Istanbul, Turkey
}

*Corresponding author

Gulten Kaptan, Istanbul Arel University, School of Health Sciences, Department of Nursing, Istanbul, Turkey, Tel: +90 8502735 / 1095;

E-mail: gultenkaptan@arel.edu.tr

Submitted: 07 Sep 2016; Accepted: 18 Sep 2016; Published: 23 Sep 2016

\begin{abstract}
The present study presents the findings about domestic violence women experienced by their husbands in 2015 in Turkey. A total of 50 women between the ages of 18 and 50 participated in the study. They answered the questions about physical, psychological, and sexual violence which they experienced by their husbands, on social media. The findings of the study have shown that all participants have been exposed to physical, psychological or sexual violence at least once.
\end{abstract}

Various risk factors related to violence against women have attracted attention: alcohol; the idea of that men have the right to control women; men's excessive instinct of aggression; insufficiency emotion that the men contain within their personality (men's excessive instinct of inferiority); insufficient education intended for avoiding violence during the school years and in family and the perception of violence as a sign of male superiority. However, women have explained their reasons to accept violence as their lack of economic freedom and the family's economic problems, their desire to have children and to maintain the integrity of the family by following the customs and traditions.

It has been observed that women react to violence by responding to their husbands with physical violence, leaving the environment, trying to forget the violence by concentrating on different activities and accepting violence. The data of the study revealed that none of the women who are subjected to violence have reported violence and thought to get help from any official institutions. The necessity of violence prevention policies, the importance of early intervention of harassment and violence experienced in childhood and educations about violence have been discussed. The data collected in the present study is intended to contribute to the studies conducted to prevent violence against women and to create a positive change even if on a small scale.

Keywords: Violence, Women, Turkey, Insufficient education.

\section{Introduction}

There is no society which has not been affected by violence. Violence is a very serious and universal problem that deforms the basic structure of society and threatens the health and happiness of all individuals [1]. Violence is a social interference in the genetically programmed feelings, thoughts, sensing and/or behavior of another organism [2].

Violence against women has been observed in various forms: physical, sexual, psychological and economic. Violence affects individuals during the period from prenatal stage to old age [3].

A research in 2012 showed that 465.000 people had been murdered and $60 \%$ of these deaths were women between the ages of 15 and 44. This rate has been observed in the Mediterranean countries as
$30 \%$ and between $70-75 \%$ in Africa and southern East Asia. In the report covering 133 countries, the incidence rate of violence against women is reported as $51 \%$ and the rate of the most common violence form as $57 \%$ and the rate of sexual violence as $51 \%$. In Turkey, it has been reported that there are types of violence such as interpersonal, sexual, child mistreatment and sexual abuse, elder abuse [4].

According to the research made in Turkey in 2008, each four in every ten women are subjected to violence by their husbands. It is expressed that,in İstanbul, $4 \%$ of the women have experienced only sexual violence, $25 \%$ of the women sexual and physical violence and $71 \%$ of the women only physical violence $[5,6]$.

In traditional societies, especially domestic violence is silenced due to the conflict with cultural life (in order not to cause any cultural conflict? not clear enough). Therefore, the violence cannot be represented and cannot be in the books [7]. 
According to the notice of women's organizations in Turkey, women continue living with violence for the sake of their children and families and these families hope to solve the problem and manage the situation.

The research conducted as a pilot study in Turkey is considered to be essential to guide women's ideas about different forms of violence they are exposed to by their husbands in Turkey.

\section{Method}

A total of 50 women between the ages of 18 and 50 were selected by random method for this study in 2015 . The participants were asked on social media seven written questions prepared by the researcher about the psychological, physical and sexual violence they experienced, and their personal responses were obtained via social media. The researcher ensured that the questions of the research had been understood by the participants. The questions in the study include the issues such as how women describe violence, the things that affect or start violence against women, the types of violence that women have experienced, women's responses to violence, the effects of violence on women, whether children have been exposed to violence between husband and wife or not and the suggestions to prevent violence. The similar responses given by the women participated in the study have been presented in groups.

\section{Results}

\section{Response of women to violence}

\section{Q. What is violence?}

Some of the individuals who participated in the study described violence as a kind of expression of oppression in society. It was considered as an instinctive situation triggered by the sudden changes in emotions. They have expressed that violence is a primitive human act and it is inversely proportional with education and becoming socialized and directly proportional with aggression. Another group who participated in the study have expressed violence as a way to influence the environment and to be accepted by society, they gave its status within political structure as an example. All individuals who participated in the study said no for violence against women and they have expressed that no home can be made without women.

\section{Does alcohol affect violence?}

All individuals participated in the study has stated that alcohol and violence influence each other and mentioned that as long as alcohol measures increase, violence measures increase. Especially the people who do not express their thoughts, who oppress themselves, and who are sceptical and lack self-confidence can show unrestrained violence when they take much alcohol.

A married woman participant with a daughter has expressed her involvement in violence related to alcohol with these sentences: "When he does not drink alcohol he is a good and kind person but when he takes a sip of his alcohol, especially if it is vodka, he turns into a monster. In the early years of my marriage, I was arguing with my husband and responding him when he drank vodka and got angry. These quarrels used to end up with mutual violence. Not only me but also furniture could be exposed to violence. As my furniture is precious to me. I used to attack him when he damaged any of my furniture. He usually was the winner of the night because of his physical superiority. This ordeal was going on till the night. I gave birth to a healthy baby girl. I do not respond to him anymore no matter what he does to provoke me. I keep my silence. If necessary, I lock myself in the bathroom etc. From now on, my daughter is a great supporter of me."

\section{Is violence associated with the perception of religion?}

The individuals who participated in the study have expressed that women and men have not been created with different values but been created as equally human, and they mentioned if women and men act together being aware of this, they can be the deputy of the creator.

\section{How does education affect violence?}

A group of individuals participating in the study have stated that violence can be prevented with education. They have expressed that education is not only learned in school but also it starts in the family. One of the participants of the study used the following expression "Children are like clays, they take whatever shape you give". Individuals who indicate that the father's acts against their wives affect their children's lives have thought that children are influenced by these acts if these acts include violence. They have expressed that the social acts of children growing in a family environment including violence can change a little with the help of school education. It has been mentioned that teachers who become a role model in school will help children for their adaptation to society.

The other part of the individuals who participated in the study has indicated that education and violence have no relation. They have said they witnessed that most of the women are victims of violence although they are educated. They have expressed that women become stronger with education but they are exposed to violence as they fail to show their confidence.

\section{Self-image and self-awareness}

The participants of the study have stated that people exposed to violence become aggrieved as they lack self-awareness, selfregard and cannot foresee the oncoming violence. It has been also indicated that if the man has inferiority complex, this increases his propensity for violence, and he uses violence on the people with low self-regard.

\section{Why do men use violence on women?}

The individuals who participated in the study mentioned that no type of violence committed by a living creature on another can be justified. They also mentioned that women are exposed to all kinds of violence and most commonly to psychological violence with the expression "you are a woman, you cannot do it".

One of the reasons of men's violence against women was thought 
to be the roles imposed on men in Turkish society, which consider men as the owner and the guardian of women and morality. It was indicated that the family and also the people close to the family (e.g.partner's mother and father) triggered men's violence toward women. One of the individuals who participated in the study said "When I was a child, I witnessed that my grandmother provokes my father to beat my mother. Each time my father beat my mother, she cried in a room and my father cried in another. My mother died before my grandmother. She did not give her blessing to my mother. All of them are underground. I hope they give there their blessing to each other. May God speed all three of them".

Finally, it is expressed that there is no violence in a place where love and passion exist and there is violence in the places lacking these emotions.

\section{What is the person who commit violence like?}

The individuals who participated in the study indicated that the people who use violence were exposed to violence in their childhood or saw violent behaviours in their families. The individuals who have inferiority complex or who feels inability were expressed that they are inclined to violence.

\section{Discussion}

Society-based researches give significant information about the nature of violence and measurement of violence observed in society. Researches using random sampling method have an important place among the data gathering systems used for obtaining detailed information about unjust suffering of women in society. Likewise, it was observed that the random sample method chosen in the present study is very effective in showing that violence against women is very common in Turkey.

In most of the societies in the world, violence used diversely against women means the violation of human rights and this appears as an important problem that must be prevented with regard to health, peace and continuation of the societies. The fact that all the women participated in the research are subjected to physical violence by their husbands is a sign of the prevalence of this problem in Turkey. The data collected demonstrate that physical violence is more common compared to the sexual and psychological violence men practice against their partners. It was determined that incidents of physical violence men use on their partners such as beating, kicking are repeated incidents.

According to the data collected, it was also observed that men have sexual intercourse with their partners without asking for their consent. One of the woman participated in the present research experienced physical violence (e.g. being beaten up) by her husband when she was pregnant. It is obvious that the data of the study is similar to the data of several other studies conducted in other countries. For instance, in a research conducted in the EU countries in 2014, it was determined that in a year 13 million women were subjected to physical violence and 3.7 million were exposed to sexual violence and $20 \%$ percent of these women were pregnant when they experienced this violence [9].
It was determined that excessive use of alcohol creates an important risk factor on using violence against women as expressed by the other researchers in the literature and [10-12]. Therefore, it is necessary to attach importance to preventive action for excessive alcohol use in national programs for violence prevention and avoidance. Hence, it is also necessary for alcoholic beverages industry to have a supportive role toward responsible consumption of alcohol and for the prevention of its excessive use [8].

The present study also demonstrated the fact that workingwomen who are graduated from a well-known university are constantly exposed to violence, indicating that their education status is not effective on the violence they are exposed to. As the results of the research conducted in the EU countries show, while $23 \%$ of women who are graduated from primary school are subjected to physical and sexual violence, $21 \%$ of high-school graduate and $20 \%$ of university graduate women are exposed to violence in pari-passu. In accordance with these statistics, it can be stated that the difference in educational backgrounds does not have an effect on the issue of being exposed to violence. On the other hand, as indicated in literature, there is low prevalence of violence against women if perpetrator's education level high. However, in the present research, women have stated that the educational status of men does not change the risk of using violence against women. They have indicated that if men lack self-confidence and see domestic violence during their childhood, they will effectively use violence in their adult lives $[2,8,13,15]$.

As confirmed by several recent studies in Europe, many women participated in the present research expressed that violence against women increases if the family's economic condition is not good.

Some of the women in this research have suggested that education should start while the children were in her/his mother's womb, and continue in the family to prevent violence against women and they have said that school education is not enough to prevent violence. In addition to these, they have emphasised they believe that philanthropy and humanitarian behaviours are emotion which will prevent violence.

Health teams can have an important role in taking necessary precautions and for the recognition of violence against women as the related literature states that about $20-40 \%$ of pregnant women were exposed to physical or sexual violence by their husbands $[8,9,14]$. For this reason, health teams can play an effective role in the protection of pregnant women at risk from being exposed or subjected to violence.

According to the responses of the participants in the present research, some lost their self-confidence and felt angry and rageful due to the violence they were exposed to. Nevertheless, they did not want ask for any help on these issues. Similarly, relevant literature also revealed that women preferred not to report the violence they are subjected to or few women reported the incidents [8]. The fact that only a few of men who use violence are punished can be considered as one of the reasons of this case. As stated in 
the literature, all women in the present research preferred not to report violence and to live with violence or to forget the incident. A group of women participated in the research had the idea of sustaining their marriage even if being subjected to violence due to the traditions and customs in the society.

The choices of the participant women have shown that it is a requirement to develop united services in this field and convey them to women so as to help and protect them from being exposed to violence in Turkey.

In the future, the data obtained by extensive studies which will be conducted by including women's phrases will contribute much to better understand the nature of violence, to determine women's needs and create new and more effective strategies on the equality between men and women. In order to be effective, the legalization and practice of new strategies are required to prevent violence against women. In addition, it is believed that informing women about the protective laws and services will play a significant role for their protection of themselves from violence.

\section{Acknowledgements}

This research did not receive any specific grant from funding agencies in the public, commercial, or not-for-profit sectors.

\section{References}

1. World Health Organization (2002) World report on violence and health: summary, Geneva.

2. Burrowers RJ (2011) Why Violence (8th edn) Australia.

3. United Nations Secretary-General's Campaign Unite (2009) Violence against women. Department of Public Information DPI/2546A.

4. World Health Organization (2014) Global Status Report on Violence Prevention. Luxembourg.
5. Başbakanlık Kadının Statüsü Genel Müdürlüğü TC (2009) Türkiye'de kadına yönelik aile içi şiddet. Ankara, Elma Teknik Publishing House.

6. Türkiye İstatistik Kurumu (2012) İstatistiklerle kadın. Ankara, Türkiye İstatistik Kurumu Matbaası.

7. Asian Pacific Institute on Gender-Based Violence (2015) Culture \& Gender-Based Violence.

8. European Union Agency for Fundamental Rights (2014) Violence against women: an EU-wide survey.

9. Devries KM, Kishor S, Johnson H, Stöckl H, Bacchus LJ, et al. (2010) Intimate partner violence during pregnancy: analysis of prevalence data from 19 countries. Reprod Health Matters. 18: 158-70.

10. Galvani S (2006) Alcohol and domestic violence: women's views. Violence Against Women 12: 641-662.

11. Fulu E, Warner X, Midema S, Jewkes R, Roselli T, et al. (2013) Why Do Some Men Use Violence Against Women and How Can We Prevent It? Quantitative Findings from the United Nations Multi-country Study on Men and Violence in Asia and the Pacific. Bankok: UNDP, UNFPA, UN Women and UNV.

12. Luca DL, Owens E, Sharman G (2014) Alcohol Consumption and Violence Against Women.

13. Choenni V, Hammink A1, van de Mheen D2 (2015) Association Between Substance Use and the Perpetration of Family Violence in Industrialized Countries: A Systematic Review. Trauma Violence Abuse.

14. National Coalition against Domestic Violence. Pregnancy and Domestic Violence Facts. Washington.

15. Jewkes R (2002) Intimate partner violence: causes and prevention. Lancet 359: 1423-1429.
Copyright: (C2016 Kaptan G, at al. This is an open-access article distributed under the terms of the Creative Commons Attribution License, which permits unrestricted use, distribution, and reproduction in any medium, provided the original author and source are credited. 